\title{
CPAP acceptance and adherence among patients diagnosed with obstructive sleep apnea: A long-term study from eastern India
}

\section{Aloke Gopal Ghoshal, Anupam Patra, Susmita Kundu Avik Ghoshal, Dhrubajyoti Roy, Mita Roy Sengupta, Supriya Sarkar}

1,3,5\&6. Faculty, National Allergy Asthma Bronchitis Institute, Kolkata.

2. Residential Medical Officer cum Clinical Tutor, R.G.Kar Medical College, Kolkata.

4. Junior Faculty, National Allergy Asthma Bronchitis Institute, Kolkata.

7. Professor, N.R.S Medical College, Kolkata

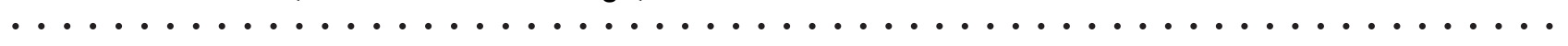

DOI No: 10.5958/0974-0155.2015.00004.2

\begin{abstract}
Background: Continuous positive airway pressure (CPAP) is considered to be the gold standard for the management of obstructive sleep apnea (OSA). But poor CPAP adherence is the main limiting factor of the OSA treatment.

Objectives: To find out the acceptance and adherence of CPAP use in patients with OSA and the association of personal and disease characteristics of the patients with patterns of CPAP use.

Methods: A cross-sectional retrospective study was conducted between June 2014 and December 2014 at the PULSAR, a sleep laboratory in Kolkata, India. Patients diagnosed with OSA between July 2007 and June 2011 at the PULSAR were included and analyzed applying a telephonic questionnaire.

Results: A total of 523 patients had undergone polysomnography. Of them, 514 (98.3\%) patients were prescribed CPAP; 40(7.6\%) were dead, and $36(6.9 \%)$ could not be contacted. of the $438(83.7 \%)$ patients contacted over the phone, $25(4.8 \%)$ refused to participate in the study. The rest, that is, $412(79 \%)$ patients, that agreed to be interviewed were divided into three groups-group I: never used CPAP (134, 25.6\%); group II: ever used CPAP (27, 5.2\%); and group III: currently using CPAP $(252,48.2 \%)$. The mean age of the patients was $50.5 \pm 11.2$ years; the mean body mass index of the group was $30 \pm 5.3$. The mean apnea-hypopnea index was $62.3 \pm 20.1$, with a range of 8.5-127.9. The mean duration of use in ever-used group was $21.6 \pm 8.4$ months and in current-user group was $54.8 \pm 16.0$ months. Mechanical discomfort $(34.3 \%)$ is main cause of non-adherence.

Conclusion: About one-third patients prescribed CPAP never initiated the treatment, and those who started reported a high incidence of adherence during the period of this study. A significant correlation was observed between disease severity and the duration of CPAP use.
\end{abstract}

Keywords: Adherence, Acceptance, Sleep apnea, Obstructive, CPAP.

Address for correspondence

\section{Dr. Anupam Patra}

2/15A, Bijoygarh, Jadavpur,

Kolkata, West Bengal 700032, India.

E-mail:dranupam.patra@gmail.com

The authors have no conflict of interest to declare 


\section{Introduction}

C ontinuous positive airway pressure (CPAP) remains the gold standard for treatment of obstructive sleep apnea (OSA), providing significant subjective improvements and reductions in cardiovascular morbidity and mortality. ${ }^{1}$ However, central to good clinical outcome in patients undergoing treatment with CPAP is compliance, which refers to how long the patient uses CPAP on a nightly basis. Despite improvements in the technology in CPAP machines, most patients still experience difficulties in tolerating the machine and/or mask. Inconvenience during titration causes a large proportion of patients from ever using the CPAP therapy. ${ }^{2}$ Even among patients that continue treatment despite inconvenience, some stop the treatment without a consent from their treating physicians.Controversies exist as to the relation of the severity of the disease to the level of adherence. Some studies suggest that the level of compliance is related to the severity of the disease and to the initial inpatient management session. ${ }^{3,4} \mathrm{With}$ respect to the compliance, the first few weeks are critical, as well. ${ }^{5}$

Weaver and Grunstein ${ }^{6}$ estimated that, at 3 months of treatment, $29-83 \%$ of patients detected with OSA were nonadherent, when nonadherence is defined as a mean of $\leq 4 \mathrm{~h}$ of use per night. At the end of a year, nearly half of the patients were not using CPAP. In a prospective cohort study of 25 patients with newly diagnosed OSA, MartínezGarciaet al. ${ }^{1}$ measured the CPAP adherence at 18 months and found that the majority $(91.6 \%)$ of those patients were not using CPAP at all.

This study was conducted in a large sleep laboratory in Kolkata, India, to investigate the current patterns of CPAP adherence in patients with OSA and the association of personal and disease characteristics of the patients with patterns of CPAP use. We also attempted to explore the reasons for nonuse of CPAP in these patients with OSA from the time of their initial or subsequent use.

\section{Materials and Methods}

\section{Study Setting and Duration}

The study was conducted between June 2014 and December 2014 at PULSAR (Pulmonary Laboratoryand Sleep Associated Research), a sleep laboratory in Kolkata, West Bengal, India.

\section{Polysomnography and CPAP titration}

Before the start of polysomnography (PSG), the procedure was explained in full details by the sleep technician of the institute. Any problems encountered by the patient or the machine during the night were promptly solved by the technician during the titration night. PSG done at PULSAR included an EEG, binocular electrooculogram, chin and lower leg electromyogram, nasal and mouth airflow, thoracic and abdominal respiratory movements, ECG, and oxygen saturation measured by pulse oximetry. A complete cessation of airflow for $\geq 10 \mathrm{~s}$ was taken as the definition of apnea, while hypopnea was defined as a $\geq 50 \%$ reduction in oronasal airflow accompanied by a reduction in oxygen saturation measured by pulse oximetry of at least $4 \%$. Apnea events were classified as obstructive, mixed, or central, according to the presence or absence of breathing efforts with thoracoabdominal paradox. Apnea-hypopnea index (AHI) was determined by the number of apnea and hypopnea events per hour during the night of PSG procedure. Other measured data comprised including arousal index and minimal oxygen saturation. After PSG, patients underwent a titration of CPAP trial if determined necessary by the physician at the institute. If the patients decided to accept CPAP, the patient was introduced to the medical equipment providers by the technical staff at PULSAR.

\section{Study population}

Records of patients diagnosed as OSA between July 2007and June 2011 at PULSAR were analyzed. Baseline characteristics of patients and sleep study findings were recorded on prestructured schedules after removing all identifiers. All eligible patients by records retrieved from the database were contacted by one of the investigators (AP) and asked to take part in the study. No surrogate interviews were taken, and patients that were dead as informed by the relatives, did not respond after two attempts, or in all those who could not be contacted were excluded from the study. The study was approved by our Institutional Ethics Committee.

The same schedule used for collection of recorded data also had a section of telephone questionnaire that consisted of eight questions that took approximately 10 min to answer. The questions were pilot tested on 10 patients (diagnosed after the study period) to ensure easy comprehension and changes made accordingly. The same 
interviewer (AP) experienced in telephone- and population-based surveys conducted the telephonic interviews for all patients from a script to ensure consistency among all the interviewees.

\section{Definitions}

Acceptance: Patient meets the selection criteria for CPAP treatment and proceeds to have CPAP pressure level determined.

Adherence: In this study, the study population was divided into those with "adherence" to CPAP ( $\geq 4$ h CPAP use per night) and those with "nonadherence" to CPAP $(<4$ h CPAP use per night)for more than $70 \%$ of the nights ${ }^{8}$ for the last 6 months.

The study population was divided into three groups based on their pattern of CPAP use:

- Never used-Group I: Patients that were prescribed but never initiated on CPAP therapy.

- Ever used-Group II: Patients that have been prescribed CPAP by the treating physician at PULSAR and had been adherent to CPAP for 6 months or more but had stopped using it for more than 6 months from the time of questionnaire administration.

- Currently using-Group III: Patients that have been prescribed CPAP by the treating physician at PULSAR and had been adherent to CPAP for 6 months or more and is currently using it or has stopped using for less than 6 months. The patients of this group were asked about their adherence to the treatment.

\section{Results}

A total of 523 patients had undergone PSG at PULSAR between July 2007 and June 2011. Of them, nine (1.7\%) patients were not prescribed CPAP based on the disease severity. Of the $514(98.3 \%)$ patients who were prescribed CPAP, $40(7.6 \%)$ patients were dead at the time of data collection, and $36(6.9 \%)$ patients could not be contacted because of change in telephone number not intimated to PULSAR. Of the $438(83.7 \%)$ patients that could be contacted over the phone, 25 (4.8\%) refused to participate in the study. The rest, that is, $412(79 \%)$ patients that agreed to be interviewed, were divided into three groups-group I: never used CPAP (134, $25.6 \%)$;group II: ever used CPAP $(27,5.2 \%)$;and group
III: currently using CPAP (252, 48.2\%) (Figure 1).

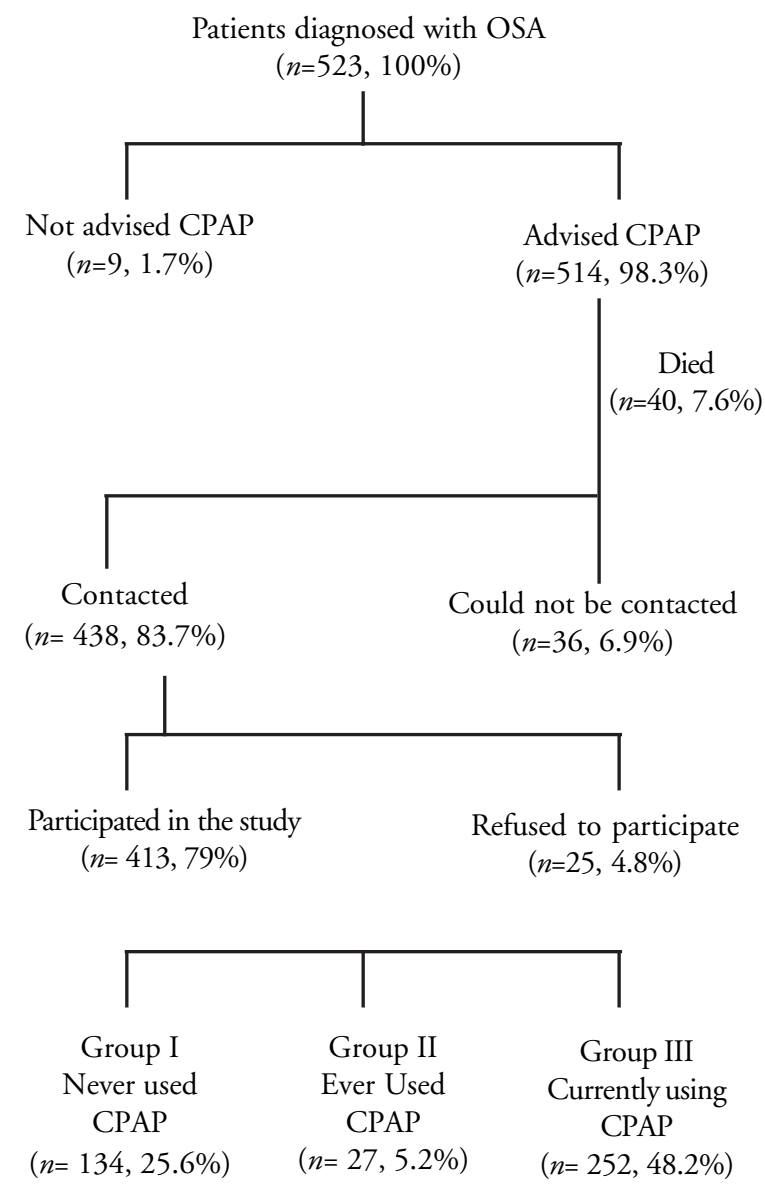

Figure 1: Flow chart depicting patient recruitment for this study

Table 1: Baseline characteristics of patients diagnosed with OSA that participated in the study $(n=413)$

\begin{tabular}{|l|l|l|}
\hline Patient characteristics & Mean & Range \\
\hline Male/female, $n$ & $359: 54$ & NA \\
\hline Mean age, years & $50.5 \pm 11.2$ & $11-87$ \\
\hline Mean BMI, kg/m ${ }^{2}$ & $30 \pm 5.3$ & $19.1-64.3$ \\
\hline Mean AHI & $62.3 \pm 20.1$ & $8.5-127.9$ \\
\hline
\end{tabular}

The baseline characteristics of all the patients with OSA are presented in Table 1 . The mean age of the patients that were interviewed was $50.5 \pm 11.2$ years; the minimum age at which CPAP was prescribed was 11 years while the eldest person was 87 years at the time of diagnosis. The mean body mass index (BMI) of the group was $30 \pm 5.3 \mathrm{~kg} / \mathrm{m}^{2}$. The mean AHI was $62.3 \pm$ 20.1 , with a range of 8.5-127.9. 
Table 2 shows the differences in baseline characteristics and symptoms between the three groups of patients. The proportion of patients with symptoms were higher in group III compared with those in groups I and II.

Table 2: Differences in baseline characteristics and symptoms of patients diagnosed and advised CPAP

\begin{tabular}{|l|l|l|l|}
\hline Characteristic & $\begin{array}{l}\text { Never-used } \\
\text { CPAP } \\
(n=134), \\
\text { group I, } \\
n(\%)\end{array}$ & $\begin{array}{l}\text { Ever-used } \\
\text { CPAP } \\
\text { group II } \\
(n=27) \\
n(\%)\end{array}$ & $\begin{array}{l}\text { Still using } \\
\text { CPAP } \\
(n=252), \\
\text { group III, } \\
n(\%)\end{array}$ \\
\hline $\begin{array}{l}\text { Age (years), } \\
\text { mean } \pm \text { SD }\end{array}$ & $49.4 \pm 12.2$ & $48.4 \pm 9.0$ & $51.4 \pm 10.8$ \\
\hline Female sex & $17(12.7)$ & $4(14.8)$ & $33(13.1)$ \\
\hline Smoking history & $63(47)$ & $16(59.3)$ & $155(61.5)$ \\
\hline $\begin{array}{l}\text { Regular alcohol } \\
\text { intake }\end{array}$ & $23(17.2)$ & $5(18.5)$ & $64(25.4)$ \\
\hline Snoring & $127(94.8)$ & $26(96.3)$ & $247(98.0)$ \\
\hline Witnessed apnea & $32(23.9)$ & $8(29.6)$ & $109(43.3)$ \\
\hline EDS & $99(73.9)$ & $26(96.3)$ & $243(96.4)$ \\
\hline
\end{tabular}

Table 3: Comparison between the mean values of parameters among the three groups

\begin{tabular}{|l|l|l|l|l|}
\hline Characteristic & $\begin{array}{l}\text { Never-used } \\
\text { CPAP } \\
(n=134), \\
\text { group 1, } \\
n(\%)\end{array}$ & $\begin{array}{l}\text { Ever-used } \\
\text { CPAP } \\
(n=27), \\
\text { group II, } \\
n(\%)\end{array}$ & $\begin{array}{l}\text { Currently } \\
\text { using } \\
\text { CPAP } \\
(n=252) \\
\text { group III } \\
n(\%)\end{array}$ & $p$ value \\
\hline $\begin{array}{l}\text { Mean } \\
\text { duration of } \\
\text { use (months) }\end{array}$ & NA & $21.6 \pm 8.4$ & $54.8 \pm 16.0$ & $0.000^{* *}$ \\
\hline $\begin{array}{l}\text { Mean age } \\
\text { (years) }\end{array}$ & $49.4 \pm 12.2$ & $48.4 \pm 9.0$ & $51.4 \pm 10.8$ & 0.145 \\
\hline $\begin{array}{l}\text { Mean BMI } \\
\left.\text { (kg/m }{ }^{2}\right)\end{array}$ & $29.4 \pm 5.7$ & $29.7 \pm 5.5$ & $30.4 \pm 5.1$ & 0.204 \\
\hline $\begin{array}{l}\text { Mean neck } \\
\text { circumference } \\
(\text { cm })\end{array}$ & $38.8 \pm 2.9$ & $38.6 \pm 3.9$ & $38.5 \pm 4.0$ & 0.594 \\
\hline $\begin{array}{l}\text { Mean arousal } \\
\text { index }\end{array}$ & $47.7 \pm 14.7$ & $49.0 \pm 10.7$ & $48.6 \pm 14.7$ & 0.819 \\
\hline Minimum $\mathrm{O}_{2}$ & $81.2 \pm 8.6$ & $78.1 \pm 6.0$ & $74.2 \pm 8.6$ & $0.000^{*}$ \\
$(\mathrm{II}, \mathrm{III})$
\end{tabular}

${ }^{* *}$ Student's $t$-test.

${ }^{*}$ Statistically significant, ANOVA with posthoc
Table 3 shows the comparison in the mean values of parameters among the three groups. There is a nonsignificant difference in the mean age and mean neck circumference among the patients in the three groups. There is a significant difference between minimum $\mathrm{O}_{2}$ saturation and mean AHI among the three groups. However, this study failed to show a statistically significant difference in the BMI and mean arousal index among the patients in the three groups.

Table 4: Reasons for nonadherence in CPAP nonusers

\begin{tabular}{|l|l|l|}
\hline Reasons & $\begin{array}{l}\text { Never-used } \\
\text { CPAP }(n=134) \\
\text { group I, } n \text { (\%) }\end{array}$ & $\begin{array}{l}\text { Ever-used } \\
\text { CPAP } \\
(n=27), \\
\text { group II, } n \text { (\%) }\end{array}$ \\
\hline $\begin{array}{l}\text { Mechanical discomfort/ } \\
\text { unable to adapt to } \\
\text { CPAP or rejected at } \\
\text { CPAP titration }\end{array}$ & $46(34.3)$ & $10(37)$ \\
\hline $\begin{array}{l}\text { Significant improvement } \\
\text { following use }\end{array}$ & 0 & $9(33.3$ \\
\hline $\begin{array}{l}\text { Improved following } \\
\text { weight reduction/yoga }\end{array}$ & $40(29.9)$ & 0 \\
\hline $\begin{array}{l}\text { Improved following } \\
\text { treatment of asthma/ } \\
\text { COPD }\end{array}$ & $10(7.5)$ & 0 \\
\hline $\begin{array}{l}\text { Unable to afford } \\
\text { the device }\end{array}$ & $20(15)$ & 0 \\
\hline Did not perceive benefit & 0 & $1(3.7)$ \\
\hline Nasal sore/nasal stuffiness & 0 & $4(14.8)$ \\
\hline $\begin{array}{l}\text { Not advised on second } \\
\text { opinion }\end{array}$ & $7(7.5)$ & 0 \\
\hline Social stigma & $8(6)$ & 0 \\
\hline $\begin{array}{l}\text { Cumbersome/ } \\
\text { location change }\end{array}$ & $3(2.2)$ & $3(11.1)$ \\
\hline
\end{tabular}

Table 4 gives the reasons for nonuse of CPAP in the groups. Of the patients that never used CPAP, the main reason was mechanical discomfort and the inability to adapt to CPAP at titration (34.3\%) followed by people with improvement in symptoms following weight reduction $(29.9 \%)$. Only $15 \%$ patients were unable to afford the machine. Among patients that had ever used CPAP, persistent mechanical discomfort associated with the use of the machine (37\%) followed by patients with significant improvements in symptoms $(33.3 \%)$ were the most common causes of stopping the usage.

Indian Journal of Sleep Medicine (IJSM), Vol. 9, No. 4, 2014 


\section{Discussion}

This study divided all the patients into three groups. Similar to findings by other studies, ${ }^{9-11}$ about one-quarter patients with OSA, comprising the group I, did not fulfill the initial prescription of CPAP. Discomfort or dislike at initial experience with CPAP titration was the single most important reason for never using CPAP. ${ }^{10,11}$ In the current settings, the patients need to buy their own CPAP; hence, cost as a reason for never use was specifically looked into. Only a small section of never users cited financial constraints as a reason for never using CPAP. This finding was similar to the studies undertaken in the United States ${ }^{12,13}$ and Australia, ${ }^{14}$ in which patients were asked to buy their CPAP machines, thus arguing against a significant effect of cost to adherence to treatment. Our study contradicts the study conducted by Nagarajan et al. ${ }^{15}$ from Indiain which they found that high device cost $(36.69 \%)$ was the main reason for not using CPAP machine.Problems of noninitiation can be mitigated by ensuring patient comfort at the initial trial, ${ }^{2}$ a better acknowledgement of the patient's initial difficulties, and taking aggressive steps to minimize them.

There is a clinical impression that patients are less likely to abandon CPAP the longer they have been using it. However, in their study, McArdle et al. ${ }^{16}$ found that $29 \%$ of these patients stopped their treatment after 1 year. Similarly, Krieger and colleagues found that $20 \%$ of those who stopped treatment do so after 1 year. Rejection following the initiation of treatment (group II in this study) is much lower than the $12-25 \%$ reported in other studies. ${ }^{17,18}$ In their study, Wolkove et al. ${ }^{10}$ described these patients as being "dissatisfied" with the treatment as evidenced by switching to other forms of therapy. In this study, however, the commonest cause of discontinuation in this group of patients was a significant improvement in the symptoms. Mechanical discomfort or inconvenience was persistent in this group of patients despite continued used of CPAP (37\%).

OSA in Asian men has been found more frequently in the nonobese patients, despite the presence of severe illness, when compared with white male patients with OSAS. ${ }^{19} \mathrm{~A}$ study by Garg et al. ${ }^{20}$ from Lucknow, India, found that $44.4 \%$ patients with OSA were nonobese according to the WHO criteria of obesity for Asians. ${ }^{21}$ In this study, however, only about a quarter of the patients were nonobese using the same criteria.

Indian Journal of Sleep Medicine (IJSM), Vol. 9, No. 4, 2014
The estimated prevalence of snoring in children is $3-12 \%$, whereas OSA affects $1-10 \% \cdot{ }^{22-24}$ OSA has been reported in children younger than 2 years, and CPAP use was found to be tolerable and effective. ${ }^{25}$ The youngest patient in this study diagnosed with OSA was 11 years. However, he was a never user of the CPAP machine.

Several studies have looked into the association of variables with continued CPAP use. In this study, most symptoms of OSA were more in the currently using (group III) and ever users (group II) than the never users (group I). However, snoring was ubiquitous in its presence in all the groups and was the second most common reason for the patients seeking treatment after excessive daytime somnolence (EDS). Several studies have found that worse initial symptoms of excessive daytime sleepiness are associated with greater CPAP use..$^{3,8,15,26}$ Symptoms of witnessed apnea was present in a larger number of patients in the ever and current CPAP user groups. As apnea is a rather frightening experience, patients tended to continue CPAP use in its presence. Patients with increased age, BMI, and the mean arousal index are seen to be nonstatistically more likely for longterm CPAP use. In addition, increased severity of OSA as evidenced by the mean minimum oxygen saturation and the mean AHI are important predictors of continued use of CPAP. ${ }^{14,27}$

\section{Limitations}

The major limitation of the study is that about one-fifth of the patients could not be interviewed either because of death or inability to contact due to change in address or phone number; hence, the patterns of their CPAP use could not be ascertained. This might have affected the results of analysis. Patients tend to exaggerate CPAP use by approximately $1 \mathrm{~h}$ when compared with objective measurements. ${ }^{8,28,29}$ Because the study was undertaken during the period when objective measurement technology was not available with the CPAP machines, objective confirmation of self-reported compliance was not available for this study. Nowadays, CPAP adherence tracking system is available in all the machines. CPAP usage can be reliably determined from CPAP tracking systems. Adherence tracking systems can collect data that measure the date ranges of CPAP usage and the total number of nights the CPAP was utilized (and not utilized)and can sort the data to the percentage of nights CPAP was utilized and the percentage of nights CPAP was used $>4 \mathrm{~h} /$ night. ${ }^{30}$ Again, in patients that gave 
improvement of the symptoms as the reason for their late noncompliance, no further sleep studies for measuring PSG parameters were carried out to verify objectively their symptomatic improvement.

\section{Conclusions}

About one-third of all the patients prescribed CPAP never initiated treatment. However, among those who started, only a small section abandoned CPAP without medical consultation, while a significant number continued to use CPAP. Those who continued the usage reported a high incidence of adherence during the period of this study. There is a significant correlation between the disease severity and the continued use of CPAP. Increase in CPAP use can be achieved with better initial management and continued support to patients on CPAP.

\section{Acknowledgement}

The authors wish to acknowledge the help received from Dr Abhijit Mukherjee, Assistant Professor, Community Medicine, North Bengal Medical College for his help in the preparation of the manuscript and statistical calculations.

\section{References}

1. Martínez-Garcia MA, Soler-Cataluña JJ, Ejarque-Martínez $\mathrm{L}$, et al. Continuous positive airway pressure treatment reduces mortality in patients with ischemic stroke and obstructive sleep apnea: a 5-year follow-up study. Am J RespirCrit Care Med 2009;180:36-41.

2. Wang $\mathbf{Y}$, GaoW, Sun $M$, Chen B. Adherence to CPAP in patients with obstructive sleep apneain a Chinese population.RespirCare. 2012;57:238 -243.

3. Pépin JL, Krieger J, Rodenstein D, et al. Effective compliance during the first 3 months of continuous positive airway pressure. A European prospective study of 121 patients. Am J RespirCrit Care Med. 1999;160:11241129.

4. Rosenthal L, Gerhardstein R, Lumley A, et al. CPAP therapy in patients with mild OSA: implementation and treatment outcome. Sleep Med. 2000;1:215-220.

5. Janson C, Noges E, Svedberg-Brandt S, Lindberg E. What characterizes patients who are unable to tolerate continuous positive airway pressure (CPAP) treatment. Respir Med.2000;94:145-149.

6. Weaver TE, Grunstein RR. Adherence to continuous positive airwaypressure therapy. The challenge to effective treatment.Proc Am ThoracSoc. 2008;5:173-178.

7. Sawyer AM, Gooneratne N, Marcus CL, Ofer D, Richards
KC, Weaver TE. A systematic review of CPAP adherence across age groups: clinical and empiric insights for developing CPAP adherence interventions.Sleep MedRev. $2011 ; 15: 343-356$.

8. Kribbs NB, Pack Al, Kline LR, et al. Objective measurement of patterns of nasal CPAP use by patients with obstructive sleep apnea. Am Rev Respir Dis.1993;147:887-95.

9. Pieters T, Collad P, Aubert G, Dury M, Delguste P, Rodenstein DO. Acceptance and long-term compliance with nCPAP in patients with obstructive sleep apnea syndrome. EurRespir J. 1996;9:939-944.

10. Wolkove N, Baltzan M, Kamel H, Dabrusin R, Palayew M.Long-term compliance with continuous positive airway pressure in patients with obstructive sleep apnea. Can Respir J. $2008 ; 15: 365-369$.

11. Rauscher H, Popp W, Wanke T, Zwick H. Acceptance of CPAP therapy for sleep apnea. Chest.1991;100:10191023.

12. Hoffstein V, Viner S, Mateika S, Conway J. Treatment of obstructive sleep apnea with nasal continuous positive airway pressure. Patient compliance, perception of benefits, and side effects. Am Rev Respir Dis. 1992;145(4 Pt 1):841845 .

13. Engleman HM, Martin SE, Douglas NJ. Compliance with CPAP therapy in patients with the sleep apnea/hypopnea syndrome.Thorax.1994;49:263-266.

14. Meurice JC, Dore P, Paquereau J, et al. Predictive factors of long-term compliance with nasal continuous positive airway pressure treatment in sleep apnea syndrome. Chest. 1994;105:429-433.

15. Nagarajan R, Ranganathan L, Sundaram A, Charles MI. CPAP therapy in OSA-a gap analysis between recommendation and usage. Indian J Sleep Med. 2012;7:150-156

16. McArdle N, Deveraux G, Heidarnejard H, Engleman HM, Mackay TW, Douglas NJ. Long-term use of CPAP therapy for sleep apnoea/hypopnoea syndrome. Am J RespirCrit Care Med. 1999;159:1108-1114.

17. Stepnowsky CJ Jr, Moore PJ. Nasal CPAP treatment for obstructive sleep apnea: developing a new perspective on dosing strategies and compliance. J Psychosom Res. 2003;54:599-605.

18. Engleman $\mathbf{H M}$, Wild MR. Improving CPAP use by patients with the sleep apnoea/hypopnoea syndrome (SAHS). Sleep Med Rev. 2003;7:81-99.

19. Ong KC, Clerk AA. Comparison of the severity of sleep disordered breathing in Asian and Caucasian patients seen at a sleep disorders centre. Respir Med.1998;92:843-848.

20. Garg R, Singh A, Prasad R, Saheer S, Jabeed P, Verma R. A comparative study on the clinical and polysomnographic pattern of obstructive sleep apnea among obese and nonobese subjects.Ann Thoracic Med. 2012;7(1):26-30.

21. WHO Expert Consultation. Appropriate body mass index for Asian populations and its implications for policy and intervention strategies.Lancet.2004;363:157-163.

22. Owen GO, Canter RJ, Robinson A. Overnight pulse oximetry

Indian Journal of Sleep Medicine (IJSM), Vol. 9, No. 4, 2014 
in snoring and non-snoring children.ClinOtolaryngol Allied Sci.1995;20:402-406.

23. Hultcrantz E, Löfstrand-Tideström B, Ahlquist-Rastad J. The epidemiology of sleep related breathing disorder in children. Int J PediatrOtorhinolaryngol. 1995;32(Suppl):S63-S6.

24. Ferreira AM, Clemente V, Gozal D, et al. Snoring in Portuguese primary school children. Pediatrics. 2000; 106:E64.

25. Downey R III, Perkin RM, MacQuarrie J.Nasal continuous positive airway pressure use in children with obstructive sleep apnea younger than 2 years of age.Chest.2000;117(6):1608-1612.

26. Waldhorn RE, Herrick TW, Nguyen MC, O'Donnell AE, Sodero J, Potolicchio SJ. Long-term compliance with nasal continuous positive airway pressure therapy for OSA. Chest. 1990;97:33-38.
27. Krieger J, Kurtz D, Petiau C, Sforza E, Trautmann D. Longterm compliance with CPAP therapy in obstructive sleep apnea patients and in snorers. Sleep.1996;19:S136-S143.

28. Budhiraja R, Parthasarathy S, Drake CL, et al. Early CPAP use identifies subsequent adherence to CPAP therapy. Sleep. $2007 ; 30: 320-324$.

29. Engleman HM, Asgari-Jirandeh N, McLeod AL, Ramsay CF, Deary IJ, Douglas NJ.Self-reported use of CPAP and benefits of CPAP therapy: a patient survey. Chest.1996;109:1470-1476.

30. Schwab RJ, Badr SM, Epstein LJ, et al. An official American Thoracic Society statement: continuous positive airway pressure adherence tracking systems. The optimal monitoring strategies and outcome measures in adults. Am J Respir Crit Care Med. 2013;188:613-620. 